\title{
Stop Whining About Outsourcing!
}

David Patterson, ACM

'm sick of hearing all the whining about how outsourc-

ing is going to migrate all IT jobs to the country with

the lowest wages.

The paranoia inspired by this domino theory of job migration causes American and West European programmers to worry about India, Indian programmers to worry about China, Chinese programmers to worry about the Czech Republic, and so on. Domino theorists must think all IT jobs will go to the Republic of Elbonia, the extremely poor, fourth-world, Eastern European country featured in the Dilbert comic strip.

I'm tired of this whining for many reasons. First, even if it were true, is there anything you could do to stop it? Second, it's not true. Third, this Chicken Little rumormongering is discouraging young people from studying computer science. Finally, there are a lot more productive ways to spend your time than spreading false rumors, such as improving your job skills.

Let's pretend for a moment that the domino theory is true. What could you do to stop IT outsourcing? Remember that the I in IBM stands for International, and both IBM and Hewlett-Packard have long had employees around the world. What legislation could stop international companies from hiring overseas? In addition, if a country passes laws to reduce layoffs, it makes international companies reluctant to create jobs there, just as economists predict. Hence, the "solution" could worsen the problem.

Is the IT job migration domino theory valid?

ACM created a Job Migration Task Force to extensively examine the impact of outsourcing. (The findings should have been published by the time this article appears.) It concluded that most credible studies suggest that over the next decade, for example, about 2 to 3 percent of U.S. IT jobs will migrate each year. That is a reduction of about 20 percent over a decade-still leaving many IT jobs, but perhaps not a rosy picture.

The implicit assumption, however, is that IT jobs are not growing. The Office of Technology of the U.S. Department of Commerce reports that between 1999 and May 2004, U.S. IT employment grew 17 percent. It grew 8 percent in the last year of the survey, making it 5 percent

\section{The facts about IT}

JOB GROWTH SHOW NO

REASON TO COMPLAIN.

$$
\begin{aligned}
& \text { higher than the bubble of } \\
& 2000 .{ }^{1} \text { Presumably, out- } \\
& \text { sourcing was already hap- } \\
& \text { pening, but in any case, } \\
& \text { such growth rates swamp }
\end{aligned}
$$

predictions of the outsourcing job loss. Most think IT jobs have grown a lot since May 2004, so when they publish the 2005 data, I bet there will be another large jump. Finally, if the IT sky is really falling, then wages should be dropping, too. The compound annual growth rate of the average IT wage has been about 4 percent since 1999, and the high-end categories have been growing closer to 7 percent annually, but inflation has been just 2 percent per year. Despite the rumors, the facts say that IT outsourcing is not the job-sucking vampire that everyone has been whining about.

Nevertheless, what's the harm in spreading false rumors?

Alas, high school students and their parents believe these rumors, and they are scared about majoring in computer science. A survey of intended majors among incoming freshmen is a good predictor of graduates four to five years later. ${ }^{2}$ It predicts the computer science major will drop in popularity from 1 in 30 students in 2000 to 1 in 75 students in 2004 . The estimate for women is much worse: the drop is from 1 in 35 in 2000 to 1 in 300 in 2004, which is the lowest in the 32-year history of the survey.

Now that your time should be freed up from spreading false and damaging rumors, how could you spend it more productively?

One way is to improve your IT skills. Individuals rather than corporations are responsible for keeping their job skills up to date now, and IT is an exciting but fastchanging field. To help you maintain your attractiveness to employers, ACM has created the PDC (Professional Development Centre). As we recently announced, ACM has doubled the number of PDC offerings to 1,000 online books and 900 online courses. For the cost of one book per year (\$99), you can become an ACM member and then can choose online versions of all the O'Reilly books, Continued on page 63 


\section{Continued from page 64}

for example, as well as take hundreds of online courses. The PDC is by far the most economical way I know of to keep current.

Moreover, ACM recently created a Professions Board, and its job is to change ACM so it can better serve IT practitioners, so expect more good things for such ACM

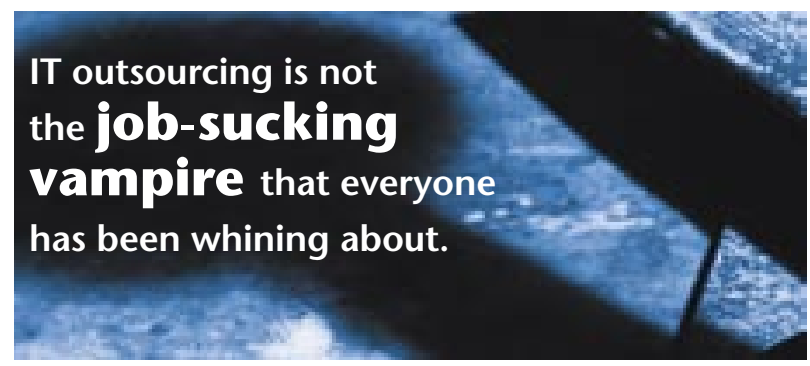

members. My article in Queue's sister publication gives more details. ${ }^{3}$ If you're interested in learning more about the new PDC or joining ACM, go to www.acm.org.

Finally, if you want to be part of the solution instead of part of the problem, please help counteract the false impression that computer science is not a good field by sharing real employment data from ACM's job migration study. Doesn't everyone in IT think it would be valuable to have a solid foundation in computing for just about anything you would want to do in the $21^{\text {st }}$ century?

But if you're not willing to help, at least stop whining about outsourcing! Q

\section{REFERENCES}

1. Patterson, D. 2005. Restoring the popularity of computer science. Communications of the ACM 48 (9): 25-28.

2. Vegso, J. 2005. Interest in CS as a major drops among incoming freshmen. Computing Research News 17 (3); http://www.cra.org/CRN/articles/may05/vegso.

3. Patterson, D. 2005. Free online books. Communications of the ACM 48 (10).

DAVID PATTERSON is president of ACM and has been professor of computer science at the University of California, Berkeley, since 1977. He is one of the pioneers of both RISC (reduced instruction set computers) and RAID (redundant arrays of inexpensive disks), has co-authored five books, and has been recognized by education and research awards from ACM and IEEE and by election to the National Academy of Engineering. In 2005 he shared Japan's Computer and Communication award with John Hennessy and was named to the Silicon Valley Engineering Hall of Fame.

(c) 2005 ACM 1542-7730/05/1000 $\$ 5.00$ 